\title{
Comparison between Variable Switching Frequency and Timer Controller with Constant Switching Frequency Techniques for PFC Converter
}

\author{
Mr. D. Lenine ${ }^{1}$, Dr.Ch. Sai Babu ${ }^{2}$
}

\begin{abstract}
This paper presents comparative review of current control techniques with variable switching frequency and constant switching frequency for the power factor correction. Operation of the Boost converter and their control schemes are described and modeled. The capacitor and inductor with voltage and current ripple with minimum ripple values was designed to absorb sinusoidal input current and to reduce total harmonic distortion (THD) in the input current with output voltage regulation. Performance of the converter is shown to relevant international standards.
\end{abstract}

Keywords-ac-dc power converter, Control Techniques, PFC, Simulation results, Comparative study and Power quality improvement.

\section{INTRODUCTION}

The Single-phase switch mode ac-dc converters are being used as front-end rectifiers for a variety of applications due to the advantages of high efficiency and power density. These classical converters, however, draw-non-sinusoidal input ac currents leading to low input power factors and injection of harmonics into the utility lines. Research in improved power quality utility interface has gained importance due to stringent power quality regulation and strict limits on total harmonic distortion (THD) of input current placed by standards such as IEC 61000-3-2 and IEEE 519-1992. This has led to consistent research in the various techniques for power quality improvement. Research into switch mode power factor corrected ac-dc converters has been in two directions namely buck and boost type topologies. On the other hand the boost type converter generates DC voltage, which is higher than the input ac voltage. However, the input current in these converters flows through the inductor and therefore can easily be actively wave-shaped with appropriate current mode control. Moreover, boost converters provide regulated dc output voltage at unity input power factor and reduced THD of input ac current. These converters have found widespread use in various applications due to the advantages of high efficiency, high power density and inherent power quality improvement at ac input and dc output. The preferred power circuit configuration of single-phase boost converter is the most popular and economical PFC converter consisting of diode bridge rectifier with step-up chopper.

This paper presents the comparative review of two current control techniques with variable switching frequency and constant switching frequency. Simulation results are provided for evolution of converter performance under study state and dynamic conditions. Finally the converters are compared on the basis of performance, efficiency, design and control complexity.

The boost topology and configuration is explained in section II.The design equation for the PFC technique components are given in section III. In section IV the simulation results are presented and the conclusion is given in the last section.

\section{CONFIGURATION}

\section{A. Current Control Techniques for PFC converters}

The current control techniques have gained importance in ac - dc converters used for high performance applications [1] Where the fast response and high accuracy are important. Various current control methods have been proposed and classified as hysteresis control, predictive control, linear control and timer controller with constant switching frequency. Principle of these methods are briefly described and discussed below [3].

\section{B. System Configuration}

The topology of Boost converter is shown in Fig.1

(a)Boost converter operates at continuous conduction mode. (b) The switching frequency is much higher than the I ine frequency. So the input voltage $V_{\text {in }}$ can be assumed as a constant during one switching cycle. (c) Moreover, the output capacitor is an efficient energy storage element.

Fig.1. Shows the configuration of such converter to improve the power quality at ac mains and dc output, reduced losses and noise, enhanced compactness by drastically cutting their weight and volume. In principle, it is a combination of diode bridge rectifier and step-up dc chopper with filtering and energy storage elements [6]. High-frequency PWM and variable switching frequency techniques are used in the closed-loop controllers in outer voltage-fed loop of these converters to provide fast response and high level of power quality at input ac mains and dc output [4].

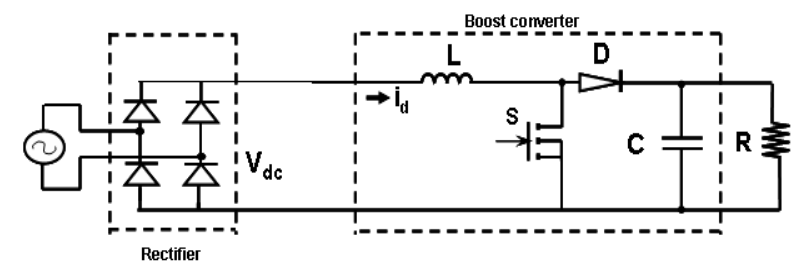

Fig 1. Diode Bridge Boost Converter 


\section{Variable switching frequency technique}

Two sinusoidal current references $I_{p} \sin \omega t, I_{c} \sin \omega t$ are generated one for the peak and other for the valley of the inductor current as shown in the fig.2.According to this control technique the switch is turned on when the inductor current goes below the lower reference $I_{c} \sin \omega t$ and is turned off when the inductor current goes above the upper reference $\mathrm{I}_{\mathrm{p}}$ sin $\omega t$ giving rise to variable frequency control. Also with this control technique the converter works in continuous inductor current mode (CICM).The inductor current ripple is $\delta$ sin $\omega t$, where $\delta$ is the peak current ripple. Since the inductor current switches at a much higher rate then the line voltage, the line voltage $i_{o}$ assumed constant in each inductor current switching cycle. Fig 2. Shows the boost inductor current with Variable hysteresis control. In this control technique the switching frequency is variable.

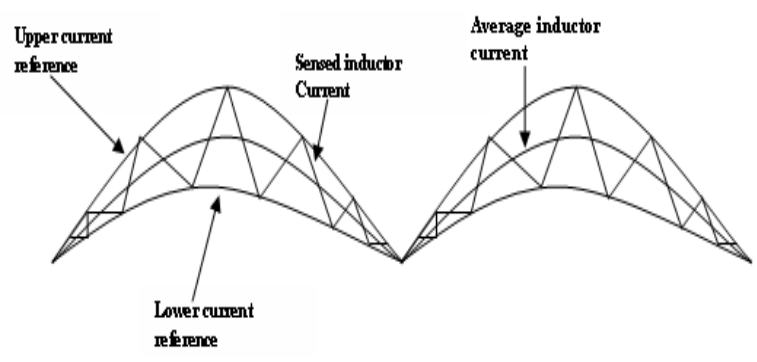

Fig 2. Boost inductor current with Variable hysteresis control

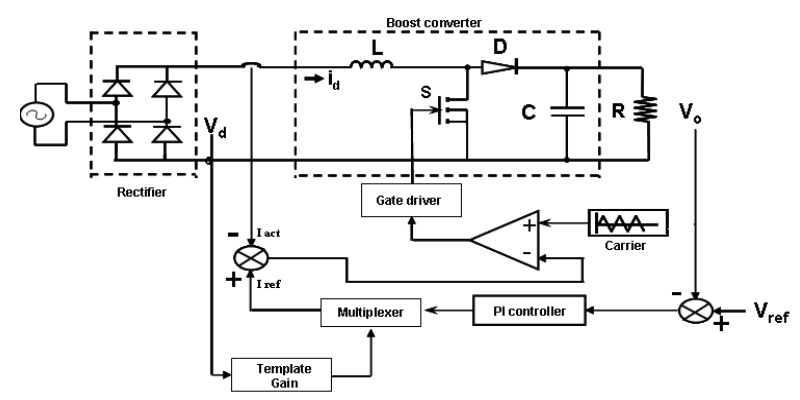

Fig 3. Variable switching frequency technique for single-Phase Boost PFC Converter

In principle it is the combination of diode bridge rectifier and step-up dc chopper with filtering and energy storage element. The Hysteresis control technique with high switching frequency are used in the closed loop controllers in outer voltage fed loop of these converters to provide fast response and high level of power quality at input ac mains and dc output. The control technique is designs so that the inductor current follows the shape of the rectified ac line voltage.To regulate the load, the error amplifier senses the variation between the output voltage and the fixed $\mathrm{dc}$ reference.This error voltage is multiplied with the sensed rectifier line voltage to control the inductor current amplitude.

\section{Constant switching frequency technique}

The fundamental idea consists in determining the ideal time period that exists between the moment when the input current crosses with the reference current and the converter commutation. Thus the input current can oscillate around the reference current with constant frequency of operation [2]

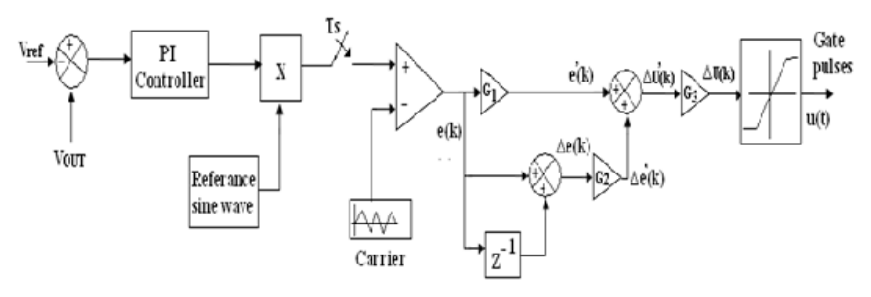

Fig 4. Constant switching frequency technique for single-Phase Boost PFC.

The above fig 4. shows the constant switching frequency technique for single phase Boost PFC. In the timer controller with constant switching frequency technique the switching frequency is constant. In this type of control strategy, the on time $t_{\mathrm{ON}}$ is varied but the chopping frequency $\mathrm{f}(\mathrm{f}=1 / \mathrm{T}$ and hence the chopping period $\mathrm{T})$ is kept constant. This control strategy is also called as the pulse width modulation control.

The variation in switching frequency basically causes three main functional problems [8]

(a) Increased high frequency ripple voltage on the output at high modulation index caused by less attenuation of the lower switching frequency's harmonics.

(b) Reduced open loop bandwidth and -loop gain, causing increased distortion as well.

(c) Increase switching losses.

\section{DESIGN OF BOOST CONVERTER}

The selection of inductor and the capacitor in the Boost topology plays a major role in the output response. The inductor is given by

$$
L=\frac{V_{S} K}{f \Delta I}
$$

Where $f$ is the switching frequency $K$ is the duty ratio, $V_{s}$ is the source voltage and $\Delta I$ is the peak to peak ripple current. The capacitor is given as

$$
C=\frac{I_{a} K}{\Delta V_{c} f}
$$

Where $f$ is the switching frequency $K$ is the duty ratio, $I_{a}$ is the output current and $\Delta V_{c}$ is the peak to peak ripple voltage.

\section{A. Determination of the objective function}

The significant subject of the Hysteresis control PFC method is how to determine the objective function. In this paper, Total Harmonic Distortion (THD) of the input current is chosen as the objective function [6]. The objective of the Hysteresis control PFC algorithm is to achieve a high power factor. The ideal situation is unity power factor. The power factor define as

$$
P F=\frac{(\text { averagepower })}{(\text { RMSvoltage }) \times(\text { RMScurrent })}
$$

In the rectifier cascaded by a PFC circuit, the displacement factor is one. So if the distortion factor approaches one. Unity power factor is realized. The relation between THD and distortion factor is expressed by 
Total harmonic distortion THD $=\frac{1}{\mathrm{~V}_{01}}\left(\sum_{\mathrm{n}=2,3 \ldots}^{\infty} \mathrm{V}_{\text {on }}^{2}\right)^{\frac{1}{2}}$

$$
\operatorname{DistortionFactor}(D F)=\frac{1}{\sqrt{1+(T H D)^{2}}}
$$

If the THD of line current is minimum, the distortion factor is maximum and the power factor become maximum too. Zero THD means unity power factor.

\section{SIMULATION RESULTS}

Simulation is performed by MATLAB/Simulink to verify the proposed Hysteresis Control technique (or) variable switching frequency technique and the constant switching frequency technique. The simulation is carried out for the input voltage of $150 \mathrm{v}$.The voltage ripple and the current ripple of the inductor and the capacitor of the Boost topology is chosen as $10 \%$ and the $20 \%$ respectively. The switching frequenc considered as 40K Hz. Fig.10 and Fig. 15 shows the input current and voltage waveforms of the variable switching frequency and constant switching frequency from these waveforms it is evident of power factor correction. Fig.11 and Fig.16 shows the harmonic spectrum of both the control techniques, the variable switching frequency technique gives the THD of 5\% and the constant switching frequency technique gives the THD of constant switching frequency technique gives the THD of $1.06 \%$.the waveforms are shown below.

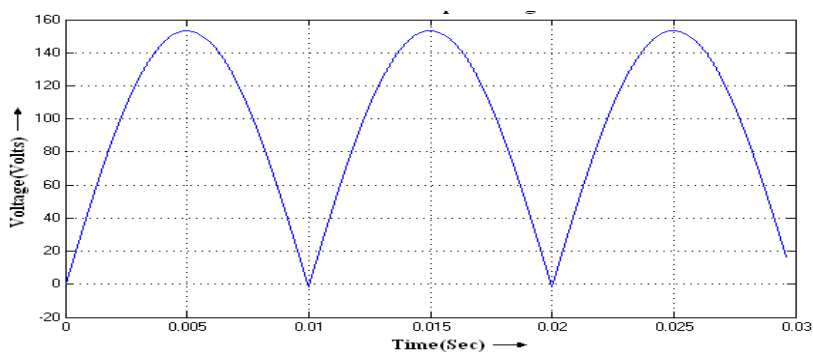

Fig 5. Output voltage waveform of diode rectifier.

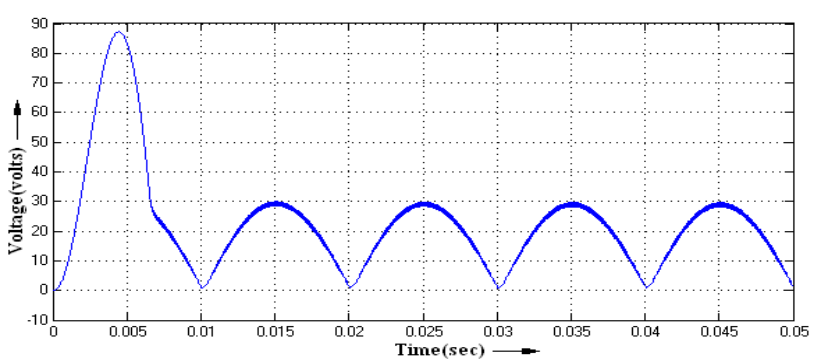

Fig 6. Inductor current waveform of variable switching frequency technique.

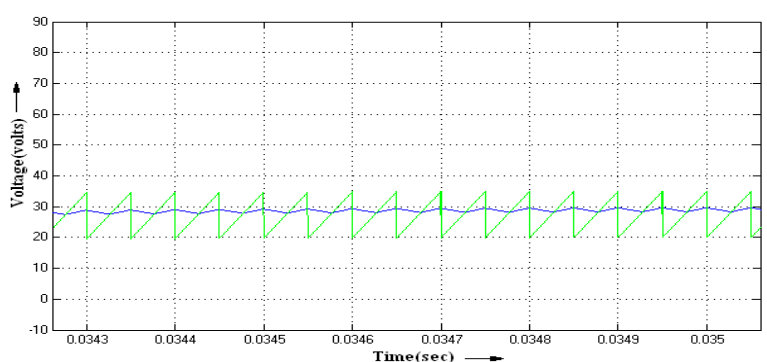

Fig 7. Comparison of carrier and PI-Controller of variable switching frequency technique.

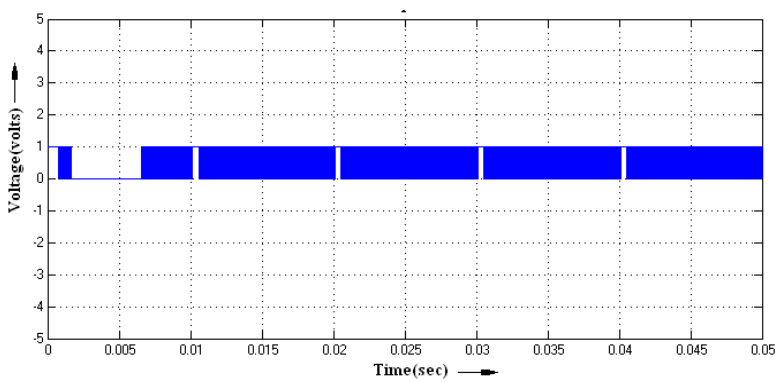

Fig 8. Gate signals waveforms of variable switching frequency technique.

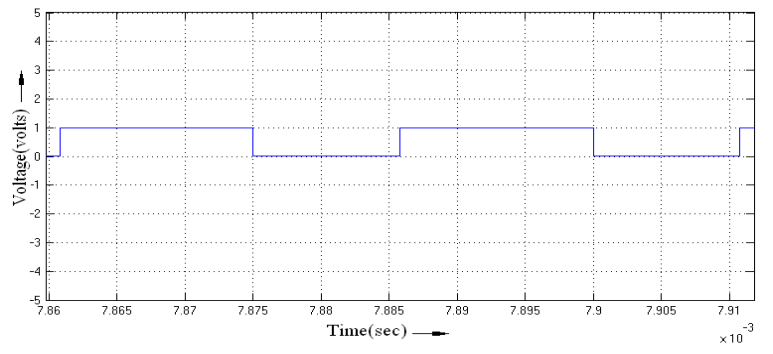

Fig 9. Gate pulses showing the variable switching frequency.

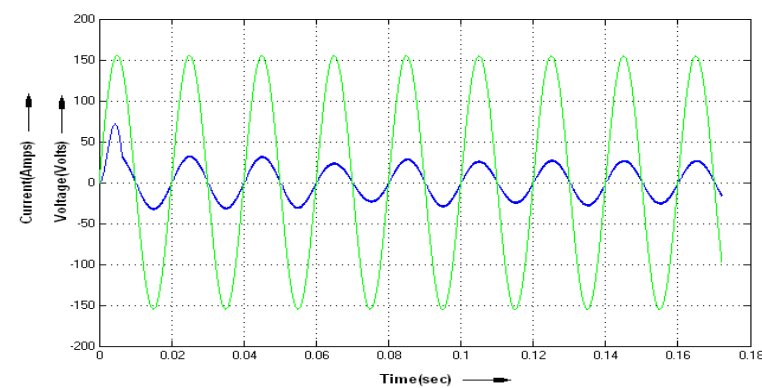

Fig 10. Simulation results of input voltage and current for variable switching frequency technique.

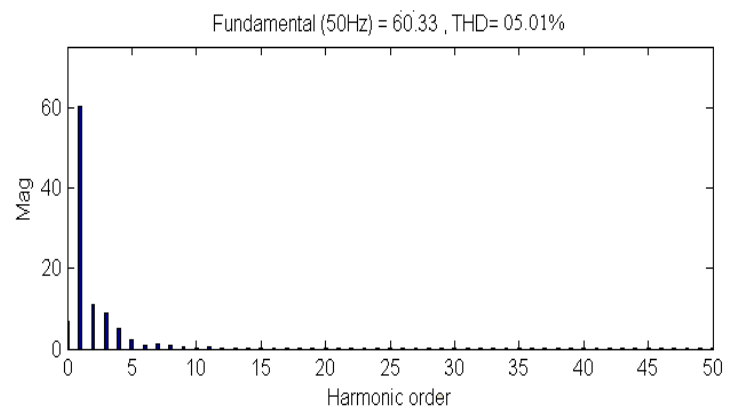


Fig 11. Input current Harmonic spectrum of variable switching frequency.

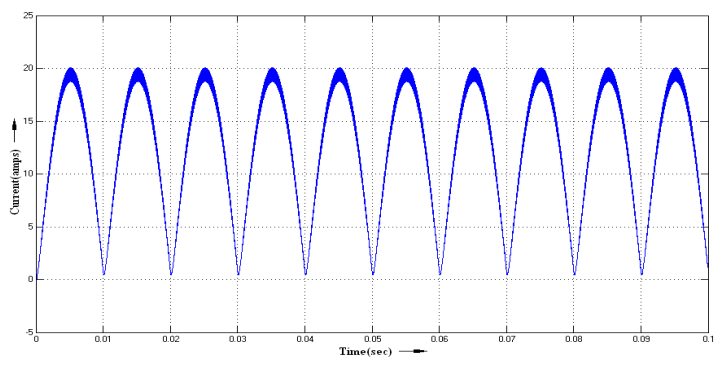

Fig 12. Inductor current waveform of constant switching frequency technique.

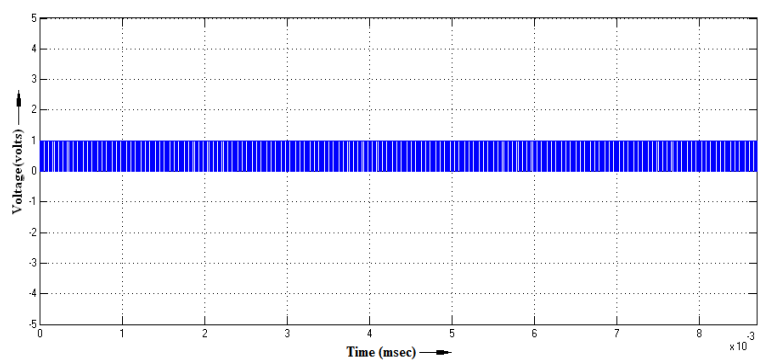

Fig 13. Gate signals waveforms of constant switching frequency technique

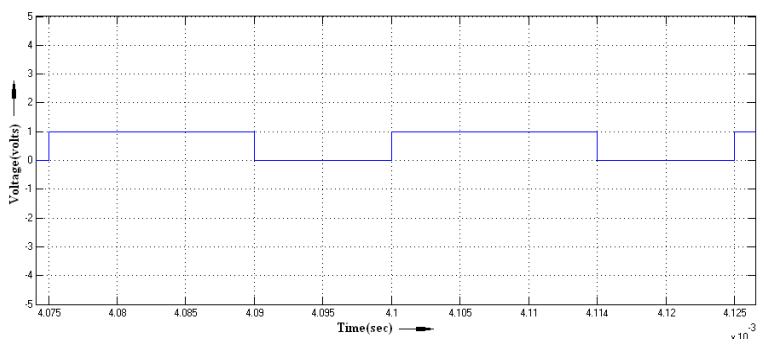

Fig 14. Waveform showing the constant switching frequency.

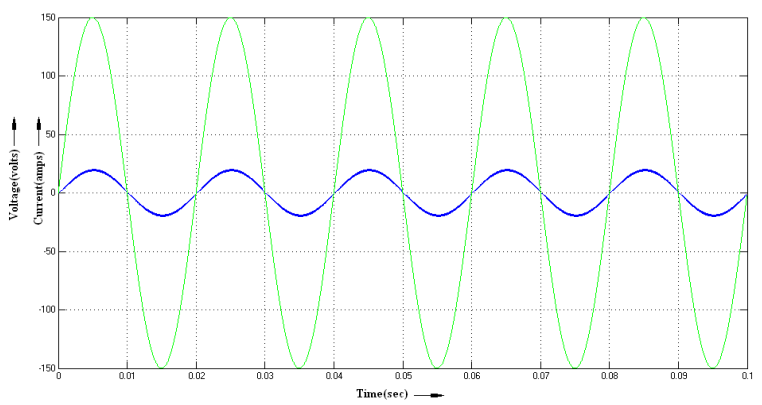

Fig 15. Simulation results of input voltage and current for constant switching frequency technique.

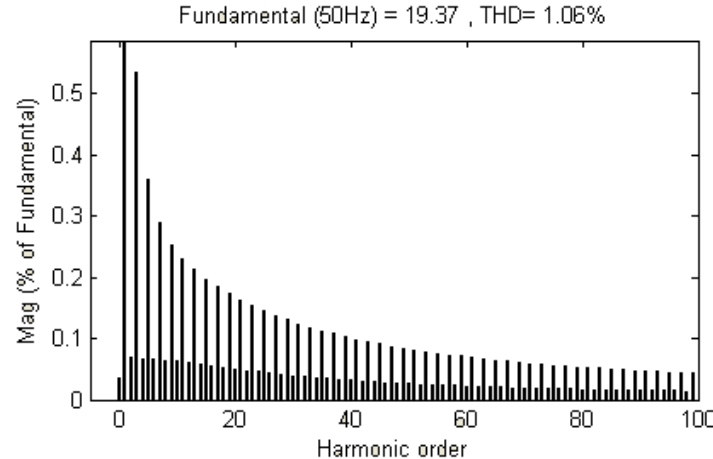

Fig 16. Input current Harmonic spectrum of constant switching frequency

TABLE I

SUMMERY OF PERFORMANCE EVALUATION FOR CONSTANT SWITCHING FREQUENCY TECHNIQUE.

\begin{tabular}{|l|l|l|l|l|l|l|}
\hline $\begin{array}{l}\text { SI } \\
\text { NO }\end{array}$ & $\begin{array}{l}\text { Input } \\
\text { voltage }\end{array}$ & $\mathrm{THD}$ & $\mathrm{DF}$ & $\begin{array}{l}\text { Power } \\
\text { factor }\end{array}$ & $\begin{array}{l}\text { Input } \\
\text { power } \\
\text { (watts) }\end{array}$ & $\begin{array}{l}\text { Output } \\
\text { power } \\
\text { (watts) }\end{array}$ \\
\hline 1 & 90 & $0.45 \%$ & 0.96 & 0.996 & 1075 & 650 \\
\hline 2 & 110 & $0.77 \%$ & 0.97 & 0.997 & 1699 & 1295 \\
\hline 3 & 150 & $1.06 \%$ & 0.99 & 0.999 & 2970 & 2701 \\
\hline
\end{tabular}

TABLE II

SUMMERY OF PERFORMANCE EVALUATION FOR VARIABLE SWITCHING FREQUENCY TECHNIQUE.

\begin{tabular}{|l|l|l|l|l|l|l|}
\hline $\begin{array}{l}\text { SI } \\
\text { NO }\end{array}$ & $\begin{array}{l}\text { Input } \\
\text { voltage }\end{array}$ & THD & DF & $\begin{array}{l}\text { Power } \\
\text { factor }\end{array}$ & $\begin{array}{l}\text { Input } \\
\text { power } \\
\text { (watts) }\end{array}$ & $\begin{array}{l}\text { Output } \\
\text { power } \\
\text { (watts) }\end{array}$ \\
\hline 1 & 90 & $4.13 \%$ & 0.95 & 0.988 & 1275 & 699 \\
\hline 2 & 110 & $4.65 \%$ & 0.98 & 0.997 & 2236 & 1650 \\
3 & 150 & $5.0 \%$ & 0.99 & 0.999 & 3375 & 2902 \\
\hline
\end{tabular}

\section{CONCLUSION}

The variable switching frequency technique is also called as hysteresis switching frequency technique. Efficiency is high for the constant switching frequency technique, power factor is almost same for the both the techniques. The total harmonic distortion (THD) is very low for constant switching frequency technique compare to that of the variable switching frequency technique. The output voltage in the case of variable switching frequency technique is $400 \mathrm{v}$ where as in the case of the constant switching frequency it $250 \mathrm{~V}$.

\section{REFERENCES}

[1] C.Zhou, R.B.Ridley and F.C.Lee, "Design and analysis of Hysteresis Boost power factor Correction Circuits", PESC conf., 1990, pp 800-807.

[2] Marcos, T.Galelli, Marcio, S.Vilela, "Proposal of a timer controller with constant switching frequency and power factor correction", IEEE, 2005.pp, 102_109 
[3] Oscar GarcíaJosé A. Cobos, Roberto Pedro Alou, and Javier Uceda, "Single Phase Power Factor Correction:A Survey", IEEE Transactions on Power Electronics, Vol. 18, No. 3, May 2003.

[4] Bhim SinghBrij N. Singh, Ambrish Chandra, , Kamal AHaddad, Ashish Pandey, , and Dwarka P. Kothari, "A Review of Single-Phase Improved Power Quality AC-DC Converter", IEEE Transactions on Industrial Electronics, Vol. 50, No. 5, October 2003.

[5] Martin F.Schlecht, Brett A.Miwa, "Active Power Factor Correction for Switching Power Supplies", IEEE Transactions on Power Electronics, Vol.PE-2, no.4, October 1987.

[6] Prasad N.Enjeti, Roberto Martinez, "A High Performance Single Phase AC to DC Rectifier with Input Power Factor Correction", IEEE Transactions on Power Electronics, October 2003.

[7] Omar Stihi, Boon-Teck Ooi, "A Single-Phase Controlled-Current PWM Rectifier", IEEE Transactions on Power Electronics, Vol.3, No.4, October 1988

[8] A.Pandey, Prof B.Singh, "Comparative Evaluation of Single-phase Unity Power Factor ac-dc Boost Converter Topologies", IEEE proc, November 30, 2004.pp, 102-109

[9] B.R Lin and T.Y.Yang "Single-phase half-bridge rectifier with power factor correction", IEEE Proc, Electrical Power Appl.Vol.151, No.4.July, 2004.pp, 443_450

[10] Aleksandar Prodic, Dragan Maksimovic: "Dead-Zone Digital Controllers for Improved Dynamic Response of Low Harmonic Rectifiers", IEEE Transactions on Power Electronics, vol. 21, no.1, January 2006.pp, 173_181

[11] 'POWER ELECTRONICS - Converters, Applications and Design', Mohan, Under land, Robbins, John Wiley \& Sons

[12] POWER ELECTRONICS - Circuits, Devices and Applications', Muhammad H. Rashid, Prentice Hall of India Private Limited

[13] 'POWER ELECTRONICS', M D Singh, K B Khanchandani, Tata McGraw - Hill Publishing Company Limited.

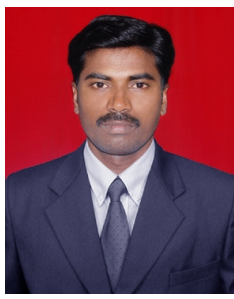

D.Lenine was born in Pondicherry, India in 1978. He received the B.Tech (Electrical and Electronics Engineering) degree from Pondicherry University, India in 2004 and the M.Tech (Electrical Drives and Control) from same University in 2006. In 2006 (October) he joined the Dept. Electrical and Electronics Engine ering, R.G.M. College of Engineering and Technology, Nandyal, as a Assistant Professor. He has published/presented six technical research papers in national and international conferences. His field of interest includes Power electronics, Electrical Drives, Digital control of electrical machines and Estimation of machines parameters.

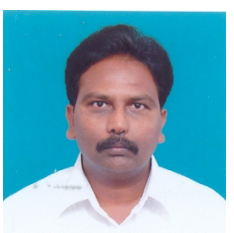

Ch. Sai Babu received the B.E from Andhra University (Electrical \& Electronics Engineering), M.Tech in Electrical Machines and Industrial Drives from REC, Warangal and Ph.D in Reliability Studies of HVDC Converters from JNTU, Hyderabad. Currently he is working as a Professor in Dept. of EEE in JNTUCEA, Anantapur. He has published several National and International Journals and Conferences. His area of interest is Power Electronics and Drives, Power System Reliability, HVDC Converter Reliability, Optimization of Electrical Systems and Real Time Energy Management. 